\title{
Some preliminary results of experiments with in-vitro culture of dipterocarps
}

W. Th. M. Smits ${ }^{1}$ and B. Struycken ${ }^{2}$

${ }^{1}$ Department of Silviculture, Agricultural University, P.O. Box 342, 6700 AH Wageningen, Netherlands

${ }^{2}$ Laboratoire de Morphologie Experimentale, ULP Institut de Botanique, 28, rue Goethe, 67083 Strasbourg, France

Received 17 Januari 1983; accepted 30 May 1983

Key-words: dipterocarpaceae, in-vitro culture, vegetative propagation

\section{Summary}

The influence of light, temperature, hormones, sugar concentrations and macrosalt concentrations on the growth and morphogenesis of different vegetative explants of dipterocarp seedlings was studied.

Terminal and axillary buds grew best on Murashige and Skoog medium at half strength. Leaf explants showed more callus formation on full strength medium.

Callus formation was best at leaf explants containing part of the midrib and taken from the lower half of the leaf.

In liquid media roots could be produced on leaf explants. Most explants survived and showed callus formation when both an auxin and a cytokinin were applied in the medium.

\section{Introduction}

The dipterocarps are trees from a family of tropical hardwood species, mainly confined to South-East Asia. Much of the wood is known as meranti, produced by the genus Shorea. Dipterocarp wood makes up about $25 \%$ of the world trade in hardwood, according to a rough estimate by Ashton (1980). Their regeneration in logged-over forest is problematic due to changes in micro-climate, soil compaction and dense secondary vegetation, whereas their gregarious flowering $(\mathrm{Ng}, 1977)$ and means of seed dispersal make their re-establishment even more difficult. If the present trend in tropical lowland forest logging continues, most dipterocarp forests are expected to be destroyed within the next two decades, except for some relicts on sites extremely adverse to logging, the 'inoperable' forests defined by Lanly \& Clément (in Oldeman, 1982).

There is a strong need for artificial silvicultural practices. However, since dipterocarp seed is produced only once every 5 to 15 years during a mast year, while just 
some individual trees flower in the years between, it is almost impossible to get a constant supply of dipterocarp planting stock by means of seedlings. Moreover, dipterocarp seeds have a short viability period (Sasaki, 1980) like many primary forest species, and their storage is problematic.

Sometimes seedlings are taken from virgin forest to be transplanted in loggedover forest with insufficient stocking of young dipterocarps. It is not only difficult to recognize the right seedlings in the forest, but the survival of these transplanted seedlings is low (Maun, 1979) and the method is expensive. Therefore methods of vegetative propagation can be of great importance for the production of dipterocarp planting stock.

At the time these experiments were conducted, the results of vegetative propagation by means of stem cuttings and air layering were still very unsatisfactory. Recently Srivastava (1981) and Smits (1983) obtained good results.

The aim of this study was the design of a basis for dipterocarp propagation by means of tissue culture. A first effort has been made to find an appropriate medium for dipterocarp culture and to obtain information on the influence of several factors on growth and morphogenesis of dipterocarp explants.

\section{Materials and methods}

Plant material was used of: Shorea curtisii Dyer ex King (from Singapore, age 5 years); Shorea cf. obtusa Wall. ex Bl. (from Indonesia, age 1 year); and Dipterocarpus grandiflorus Blanco (from Indonesia, age 2 years).

Only material of leaves and axes was taken, from the youngest sprouts available. The plant parts were submerged for a few seconds in ethanol $70 \%$, followed by 10 minutes in a $\mathrm{NaOCl}$ solution with some drops of Tween 20 added. For $S$. curtisii the $\mathrm{NaOCl}$ concentration was $1.0 \%$ and for $S$. cf. obtusa $1.5 \%$. D. grandiflorus could not be sterilized, due to a fungus that lives in its vessels. After sterilization, the leaves and axis were rinsed three times in sterile water for 5, 10 and 20 minutes respectively. Then explants were cut out of the material as shown in Fig. 1. All explants were planted half in the agar with squeezers. The explants were cultured in 80 -ml pyrex glass tubes filled with $25 \mathrm{ml}$ medium, closed with aluminium CAP-OTEST caps and sealed with PVC soil. For liquid medium with Shorea curtisii, $50-\mathrm{ml}$ pyrex Erlenmeyer conical flasks filled with $25 \mathrm{ml}$ medium were used placed on a Gyratory Shaker. Special tubes as shown in Fig. 2 were used on the 'plateau oscillant', filled with $50 \mathrm{ml}$ medium (1 oscillation/minute). As standard medium a modified Murashige \& Skoog (1962) medium was used containing: MS macro-elements $1 / 2$; MS micro-elements $1 / 1$; sucrose $3 \%$; NaFeEDTA $25 \mathrm{mg} / \mathrm{l}$; agar $7 \mathrm{~g} / \mathrm{l}$; IBA and $\mathrm{BA}$ at varying concentrations, as well as some other hormones.

Other substances were tried in the medium, such as several vitamins, myo-inositol, and adenine sulphate. The $\mathrm{pH}$ was adjusted at 6.0 before autoclaving. The media were autoclaved during 20 minutes at $115^{\circ} \mathrm{C}$. Water and filter paper were sterilized during 60 minutes at $130^{\circ} \mathrm{C}$.

The tubes with explants were placed in conditioned rooms at a constant temperature of $25^{\circ} \mathrm{C}$. When explants (mainly axial material) had been placed in light, a 


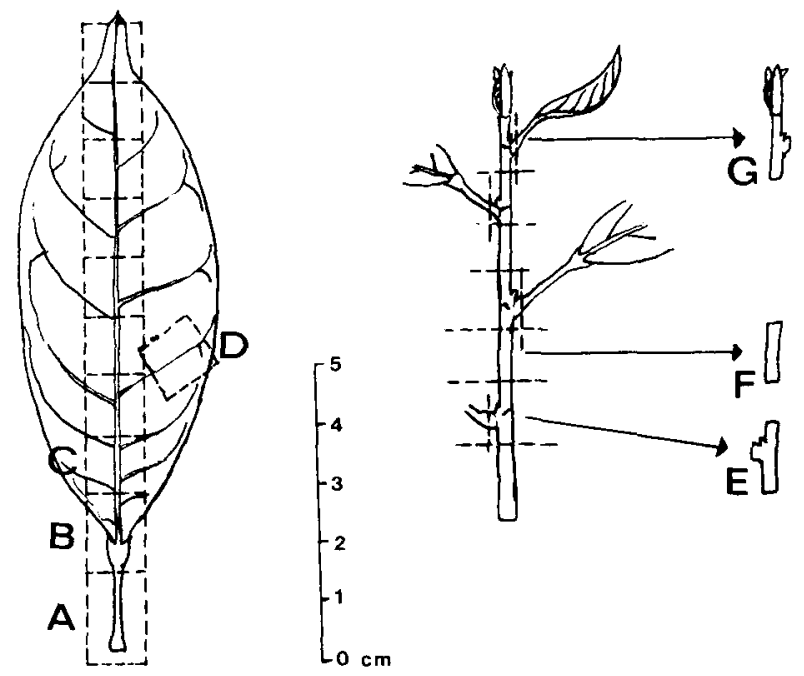

Fig. 1. Cutting of explants. The dotted lines show how the different categories are cut out of the material.

daylength of 16 hours was applied. The light intensity was approximately $10 \pm 2 \mathrm{~W}$ $\mathrm{m}^{-2}$ and was supplied by fluorescent tubes (Philips $57 / 40 \mathrm{~W}$ ). Observations concerned sprout development, neo-formation of roots and callus formation.

\section{Results}

The results obtained until now were callus and root formation on leaf explants and some sprout development from axillary buds.

Sprout development was best when the axial explants with bud were placed in light at $25^{\circ} \mathrm{C}$ on the standard medium with IBA $10^{-7}$ and BA $3 \times 10^{-6}$. Addition of thiamin $10^{-6}$ is necessary. Axial explants of $S$. curtisii were not tried.

Callus formation was best on leaf explants that were placed in darkness at $25{ }^{\circ} \mathrm{C}$ on the standard medium with MS macro-elements $1 / 1$, NaFeEDTA $50 \mathrm{mg} / \mathrm{l}$, BA 5 $\times 10^{-6}, 2,4-\mathrm{D} 8 \times 10^{-7}$ and thiamin $10^{-6}$. Subcultures of the callus were placed at the sanis conditions and medium after 6 weeks.

Root formation was obtained with leaf explants of $S$. curtisii in liquid medium. The tubes with explants were placed in light at $25^{\circ} \mathrm{C}$. The standard medium was

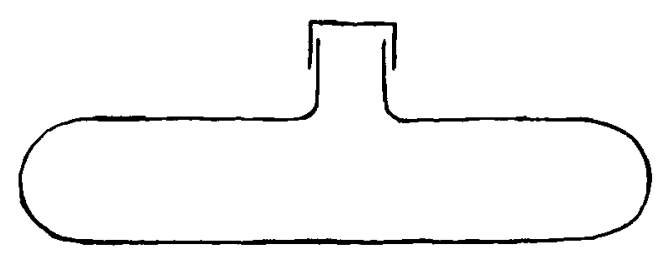

Neth. J. agric. Sci. 31 (1983)
Fig. 2. Special tubes, made for the 'plateau oscillant'. 


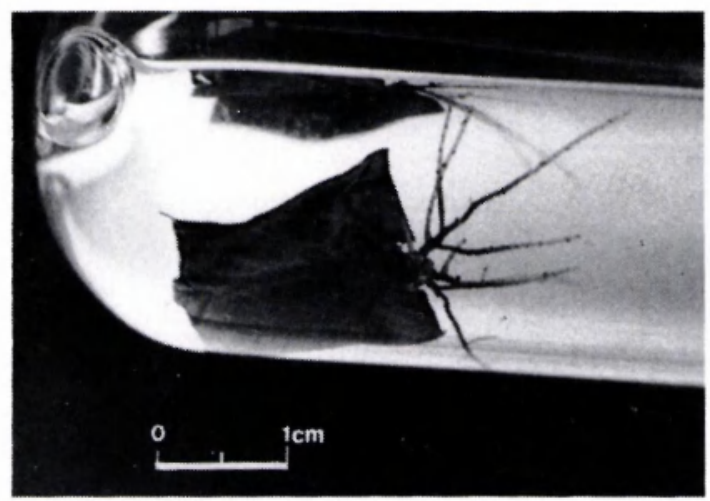

Fig. 3. Shorea curtisii, young leaf explant after 10 weeks of culture (liquid medium with NAA $10^{-6}, \mathrm{CH} 100 \mathrm{mg} /$, Yeast Extract $200 \mathrm{mg} / \mathrm{l})$.

used with MS macro-elements $1 / 1$, NAA $10^{-6}$, kinetin $10^{-6}$, myo-inositol $10^{-3}$, casein hydrolysate $100 \mathrm{mg} / \mathrm{l}$. Best results were obtained with young leaves in tubes on the 'plateau oscillant', the oscillation ascertaining aeration of the medium. Roots appeared after 5 weeks (Fig. 3).

Explants of leaves proved to be the most reactive parts of the plant with regard to callus formation. Axes without bud and petioles were found to be less reactive. Explants taken within one leaf, from its base to its top, showed a distinct gradient in reactivity. Those from the proximal part showed more callus formation than those taken from the distal part. Most callus production was noticed when leaf explants contained some part of the pulvinus (Fig. 4). This gradient was encountered with all species and in all treatments. Leaf explants containing no part of the midrib produced no callus.

When explants of dipterocarps are placed on a medium with agar, unidentified brown substances appear in the agar around the explant. When the callus grows

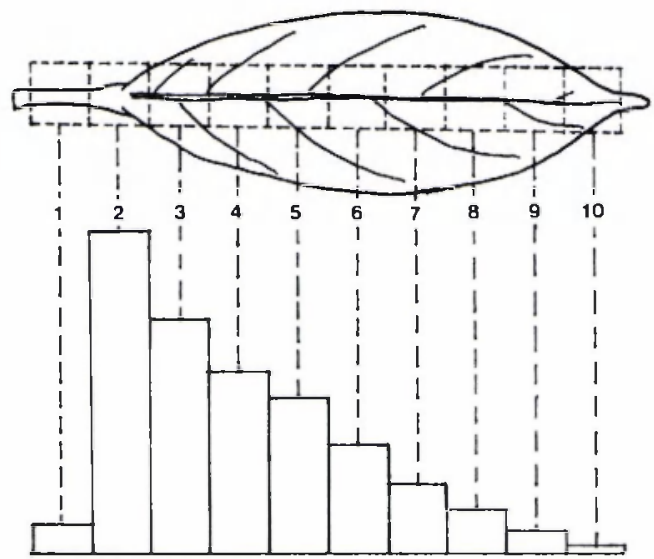

236
Fig. 4. Callus production related to topophysics in a leaf. 
faster more brown substances are produced, especially at $30^{\circ} \mathrm{C}$ and with $4 \%$ sucrose.

All experiments with $D$. grandiflorus resulted in high percentages of infection (more than $95 \%$ ). Infection of the explant was correlated with the original position of the explant in the plant (Fig. 5).

\section{Discussion}

The greatest problem and most important restriction to the reliability of the results encountered in this study has been the limited material that was available for the experiments. Therefore not all experiments have been replicated and only small numbers of explants per treatment, eleven on the average but sometimes less, could be used. For D. grandiflorus still other experiments are needed, since it seems that the high percentages of infection are caused by a fungus that lives in the vessels of the plant. This opinion finds support in:

1) the retarded start of infection (after 4 days);

2) the origin of infection (always from the vessels);

3) the appearance of the same white fungus;

4) the fact that leaves of $S$. cf. obtusa, that were sterilized in the same glass and rinsed with the same sterile water, were all sterile;

5) the fact that the youngest parts were not infected (Fig. 5);

6) and that explants with smaller veins are less infected.

It is possible that $D$. grandiglorus shows the same phenomenon as Casuarina. In

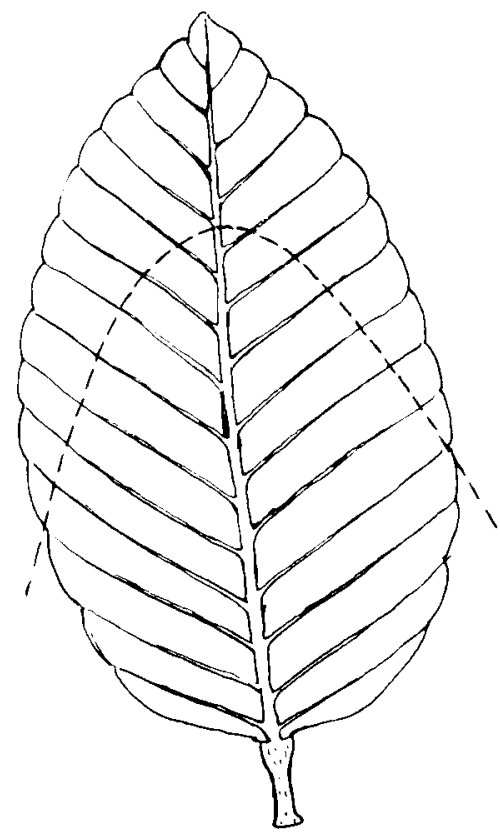

Neth. J. agric. Sci. 31 (1983)

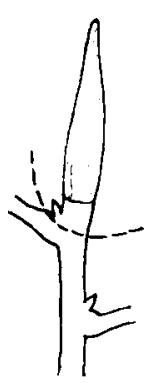

Fig. 5. Dipterocarpus grandiflorus. Only explants above the dotted lines show less then $100 \%$ infection. 
Casuarina, mycelium appears in all parts of the plants. Kelly (1950) speaks of "heriditary symbiosis'. However since in this study all material was taken from one and the same tree, no general conclusions can be drawn.

Leaves proved to be very reactive parts of the plants in vitro, but also in vivo as was found afterwards. After a soaking treatment with IBA, $S$. cf. obtusa leaves can be rooted easily, in ordinary soil. Anthony (1980) has described two types of cecidial shoots in $S$. curtisii. These shoots are in fact galls but resemble plagiotropic branches of $S$. curtisii, and are induced by Eriococcides. Therefore it was hoped that we would be able to produce complete plants, starting from leaf explants, but until now we did not succeed.

Growth of callus slows down when more brown substances appear in the agar. Liquid media or frequent transplanting may present a way to overcome this problem.

Use of 2,4-D presents the risk of mutation. Therefore it may be better to focus attention on axillary sprout development, when vegetative propagation is aimed at. Callus culture might be of importance for freeze preservation and storage of material for longer periods. Considering the speed of dipterocarp forest depletion nowadays, this last aspect deserves serious attention, in the context of gene conservation.

\section{Acknowledgements}

Thanks are due to Prof. Dr Ir R. A. A. Oldeman, Prof. Dr J. Roux, Prof. Dr Ir R. L. M. Pierik and Drs P. Evers, who made this study possible.

\section{References}

Anthony, M., 1980. Etudes bourgeonnements épiphylles déterminés par l'action d'Eriococcides cécidogènes chez les Dipterocarpacées du genre Shorea. Thèse pour le grade de Docteur-ès-Sciences à Strasbourg, soutenue le 3 juillet 1980.

Ashton. P. S. . 1980. The biological and ecological basis for the utilization of Dipterocarps. Bio-Indonesia 7: 43-53. (1. Proc. 8th World Forestry Congress, 1978). No FQL/26-16.

Kelly, A. P., 1950. Mycotrophy in plants. Waltham, Mass., USA, 206 pp.

Maun, M. M., 1979. Growth and survival of malayakal (Shorea seminis de Vries) and guijo (Shorea guiso Blume) wildlings transplanted in brushland forest (in Nueva Viscaya, Phillipines). Sylvatrop 4(3): 179-182.

Ng, F. S. P., 1981. Vegetative and reproductive phenology of Dipterocarps. Malayan Forester 44(2\&3): 197-222.

Oldeman, R. A. A. (Ed.), 1982. Tropical hardwood utilization: practice and prospects. Martinus Nijhoff/Dr. W. Junk Publishers, The Hague/Boston/London, $584 \mathrm{pp}$.

Sasaki, S., 1980. Storage and germination of Dipterocarp seeds. Malayan Forester 39(1): 13-19.

Smits, W. Th. M., 1983. Vegetative propagation of Shorea $\mathrm{cf}$. obtusa and Agathis dammara by means of leaf-cuttings and stem-cuttings. Malayan Forester (in press).

Srivastava, P. B. L. \& Penguang Manggil, 1981. Vegetative propagation of some Dipterocarps by cuttings. Malayan Forester 44(2\&3): 301-313 